\title{
Structure and Function of the Lysosomes of Human Fibroblasts in Culture: Dependence on Medium pH
}

\author{
Sverre O. Lie ${ }^{[31]}$, Brian H. Schofield, Harold A. Taylor, Jr., and Stephen B. Doty \\ Division of Medical Genetics, Department of Medicine, Orthopaedic Research Laboratory, Department of Pediatrics, \\ Johns Hopkins University, School of Medicine, Baltimore, Maryland, USA
}

\begin{abstract}
Extract
Histochemical and ultrastructural consequences of $\mathrm{pH}$ variations in growth media were studied using three normal human fibroblast strains. Histochemical staining for acid phosphatase indicated increased amounts of enzyme activity in cells grown at higher $\mathrm{pH}$. The ultrastructural consequences of an increase in growth medium $\mathrm{pH}$ was dramatic. A picture resembling storage disease developed in these cells within a few days. The cells became filled with bodies which could roughly be divided into two types. Type I had a homogeneous matrix, stained slightly with ruthenium red, was usually not membrane bound, and exhibited no acid glycerophosphatase activity. The nature and origin of these bodies is unclear. Type II bodies contained whorles of membranes and inhomogeneous matrix which was acid phosphatase positive but did not stain with ruthenium red. This type was always membrane bound and qualifies as lysosomes. Normal cells thus grown at higher $\mathrm{pH}$ were morphologically similar to cells cultured at neutral $\mathrm{pH}$ from patients with I-cell disease. These morphologic changes did not affect cell viability or cell growth.
\end{abstract}

\section{Speculation}

A morphologic picture of severe storage disease can be induced in normal fibroblasts simply by increasing the medium $\mathrm{pH}$. This is in agreement with our earlier observation that the lysosomal function of mucopolysaccharide degradation is progressively inhibited as $\mathrm{pH}$ of the growth medium increases. When attempting to diagnose genetic disease in cultured cells it is important to realize that intracellular lysosomal function is sensitive to extracellular $\mathrm{pH}$. The observation of such $\mathrm{pH}$ sensitivity might also be a useful tool in studies on the general nature of lysosomal function.

\section{Introduction}

A lysosomal storage disease [15] is a genetically determined disorder characterized by a deficiency in one of the lysosomal acid hydrolases. As a result of this defect, materials which are normally degraded are found accumulating in the lysosomes or lysosome-like bodies of the cells [16, 27]. Deficiency in each of at least 12 lysosomal enzymes has been shown to result in distinct clinical disorders [25].
Most of these lysosomal diseases can be diagnosed by measuring enzyme activities in cultured cells derived from affected patients [25]. The ultrastructure of such cells has also been the subject of numerous investigations [2, 7, 13, 27, 28], and in the so-called I-cell disease, structural abnormalities of the cultured cell is indeed one of the landmarks of the disorder [13, 18]. However, for the most part the ultrastructure of cells in culture is difficult to interpret, presumably because normal cell 
lines may at times contain all types of inclusion of pathologic appearance.

In a previous paper we have shown that the environment has a profound influence on at least one lysosomal function in normal cells [21] and that a condition mimicking storage disease can be induced in normal cells by a small change in the $\mathrm{pH}$ of the culture media. As $\mathrm{pH}$ is raised from 6.8 to 7.9 , the lysosomal degradation of mucopolysaccharides is progressively inhibited, and normal cell lines become indistinguishable from cells with genetic defects in mucopolysaccharide degradation.

This paper reports the fine structural and histochemical alterations induced in normal human fibroblasts by changes in the $\mathrm{pH}$ of the culture medium. The results support our previous observation that increase in $\mathrm{pH}$ markedly interferes with lysosomal function and produces a morphologic picture of storage disease in normal cells.

\section{Materials and Methods}

\section{Tissue Culture}

Fibroblast lines were established from skin biopsies of five normal adults (three males and two females) and one infant with I-cell disease [13, 18] and culture were maintained as monolayers in plastic culture flasks [30]. Growth medium was Eagle's Minimal Essential Medium containing $10 \%$ fetal calf serum, 100 units

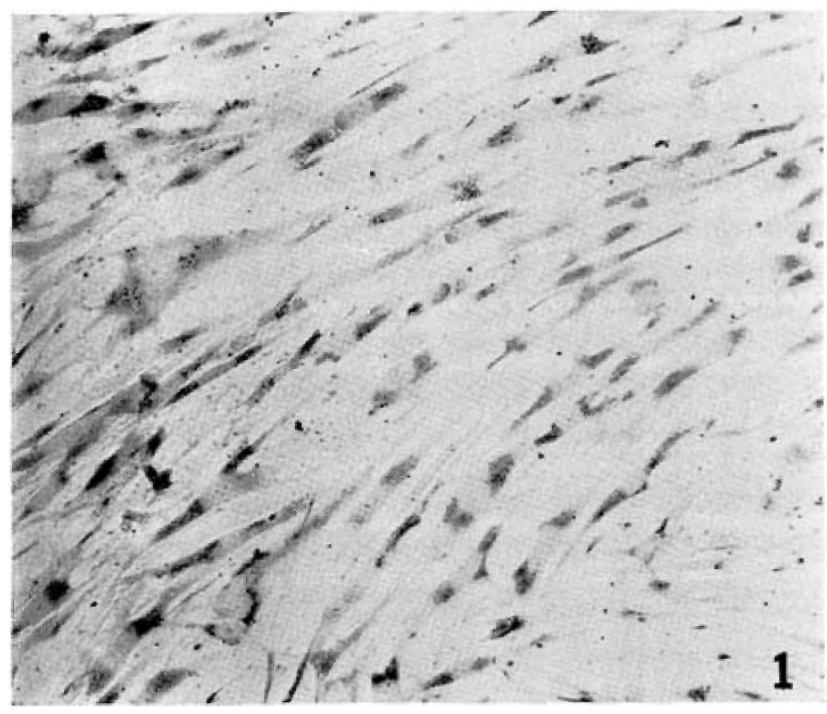

Fig. 1. Normal human fibroblast culture, seventh passage. Maintained at $\mathrm{pH} 6.8$ for 6 days. Acid phosphatase stain 15 min. $\times$ 150. penicillin and $100 \mu \mathrm{g}$ streptomycin, respectively, per ml. The desired $\mathrm{pH}$ was obtained by using organic buffers as described by Eagle [9] and incubating with air as the gas phase. Media was changed daily in order to minimize variables other than $\mathrm{pH}$.

\section{Histochemistry and Electron Microscopy}

Cells were transplanted onto coverslips and grown at the desired $\mathrm{pH}$ for $3-5$ days before examination. Experiments were timed so that samples were examined just before the cells reached confluence. Samples of each group were fixed as follows.

1. Cells were fixed in $2 \%$ glutaraldehyde in cacodylate buffer, $\mathrm{pH} 7.4$, containing $0.3 \mathrm{M}$ sucrose at $4^{\circ}$ for 60-90 min. Half of the samples were exposed to the same fixative which contained $750 \mathrm{ppm}$ ruthenium red, postfixed for $1 \mathrm{hr}$ in $1 \% \mathrm{OsO}_{4}$ containing ruthenium red, and embedded in Epon 812.

2. Cells were trypsinized and fixed as a pellet as above but without ruthenium red.

3. Coverslips were fixed as in section 1 , then incubated in acid phosphatase media [12] with $\beta$-glycerophosphate as substrate for $15 \mathrm{~min}$ at $37^{\circ}$, examined by light microscopy after brief immersion in ammonium sulfide, gently scraped from coverslips, postfixed in $1 \%$ $\mathrm{OsO}_{4}$, and embedded in Epon 812 for electron microscopy. Controls for acid phosphatase activity were incubated in the presence of 0.1 m sodium fluoride.

\section{Results}

Acid phosphatase activity as detected by histochemical staining is shown in Figures 1-3. In the cell lines studied, the histochemical activity of acid phosphatase was markedly enhanced by raising the culture medium $\mathrm{pH}$. The number as well as the size of positive granules increased (Fig. 3) and differences could be detected easily when identical cells were grown at different $\mathrm{pH}$ for only 3 days.

The ultrastructural consequences of $\mathrm{pH}$ changes in the growth medium on cultured fibroblasts are shown in Figures $4-5$. The morphology at $\mathrm{pH} 6.8$ was similar to a "normal" cell. The various organelles were well preserved, and the endoplasmic reticulum, lysosomes, and mitochondria were present in the expected amounts. At $\mathrm{pH} 7.7$, however, the picture was dramatically changed. The number of membrane-bound bodies and autophagic vacuoles was greatly increased (Fig. 5), and in some cases, filled the entire cytoplasm. There was some variation in any given sample, and 


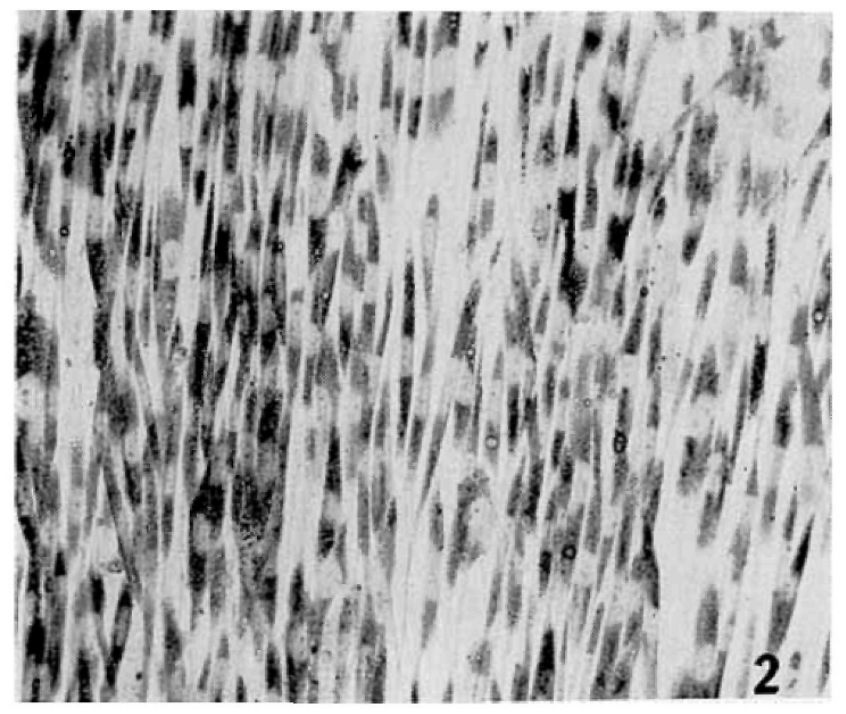

Fig. 2. Same preparation as Figure 1, but maintained at pH 7.7. $\times 150$.

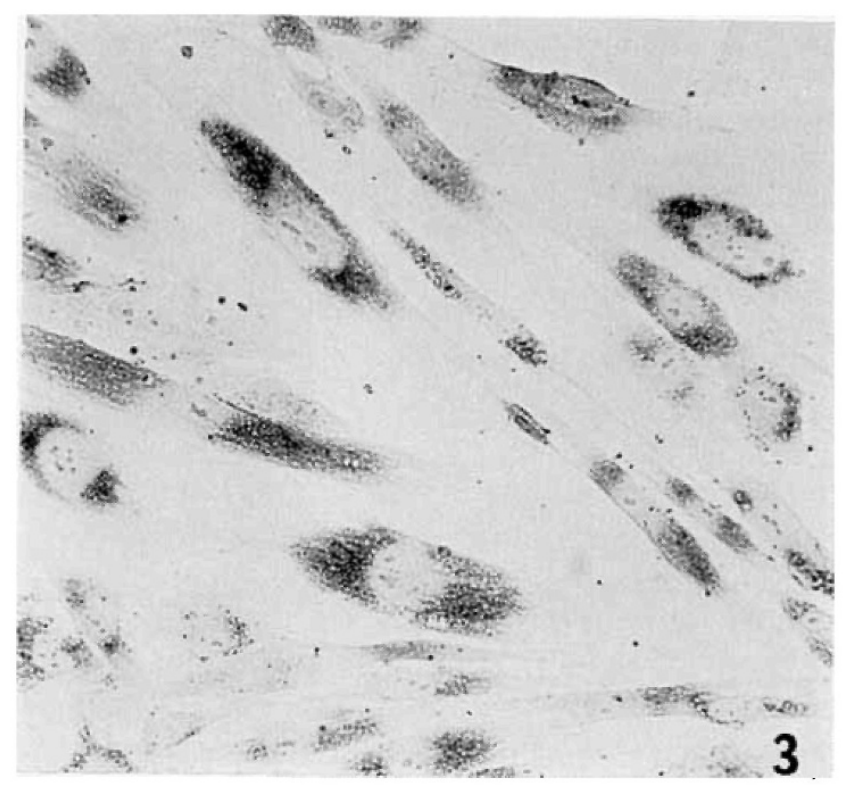

Fig. 3. High magnification of cells shown in Figure 2, showing accumulation of acid phosphatase stained lysosomes. $\times 750$.

occasional cells of normal appearance were observed (Figs. 6 and 8).

On the basis of structural and histochemical differences these bodies could be divided into two groups. One group (type I) contained a homogeneous material which stained with ruthenium red but showed no acid phosphatase activity (Figs. 6 and 7). These bodies were occasionally membrane bound, but usually had no de- tectable membrane. The second type of body (Type II) contained membraneous material and was positively stained for acid phosphatase activity (Figs. 8 and 9). These bodies always were membrane bound and did not stain with ruthenium red. Golgi elements were also stained for acid phosphatase.

It should be emphasized that these changes were not

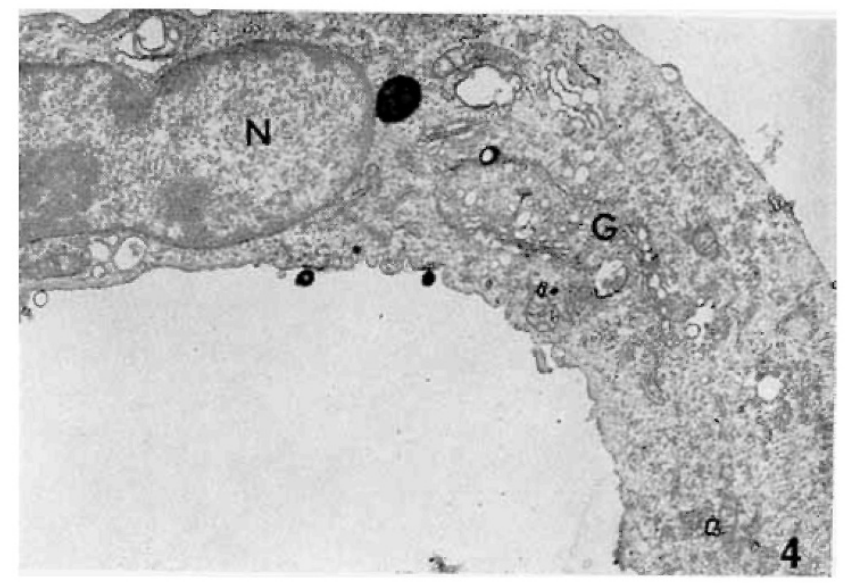

Fig. 4. Normal human fibroblast culture, seventh passage, maintained at pH 6.9 for 6 days. Ruthenium red stain. $N$ : Nucleus, L: Lipid droplet, G: Golgi. $\times 8,500$.

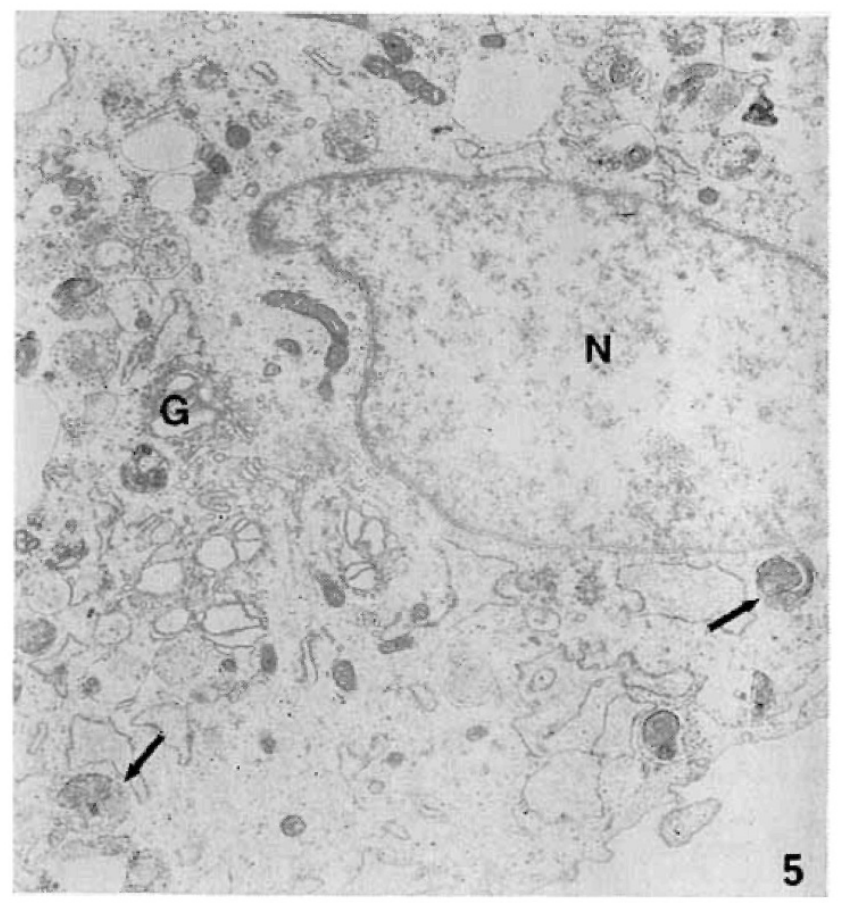

Fig. 5. Same preparation as Figure 4, but maintained at $\mathrm{pH}$ 7.7. Note presence of membrane-bound inclusions and autophagic vacuoles (arrows). $N$ : Nucleus. G: Golgi. $\times 11,000$. 


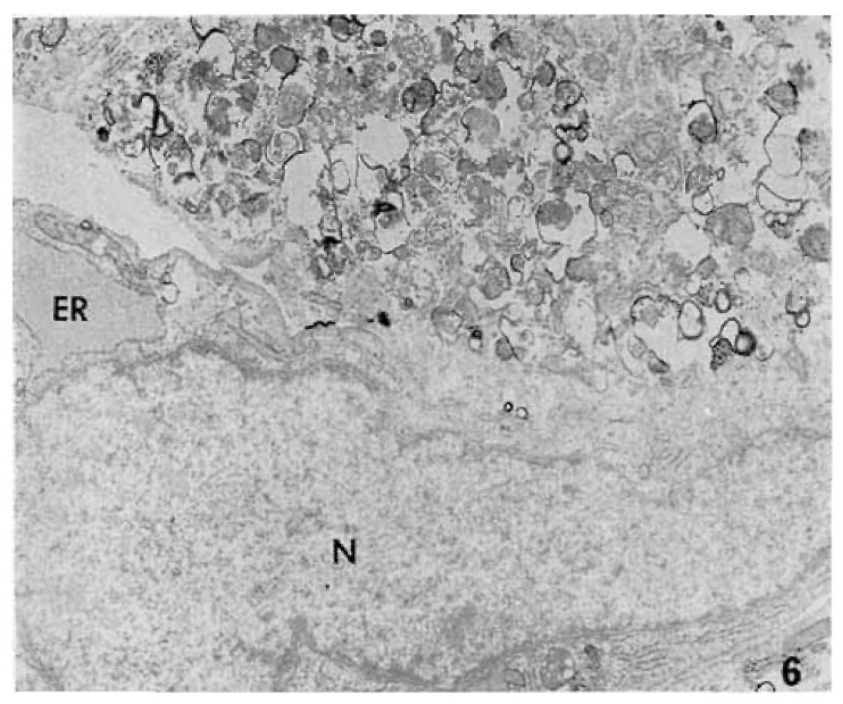

Fig. 6. Normal human fibroblast culture, seventh passage. Maintained at pH 7.9 for 6 days. Ruthenium red stain. Cell in lower half of figure appears normal, whereas cell in upper half contains large numbers of ruthenium red-stained inclusions. $X$ 11,000 .

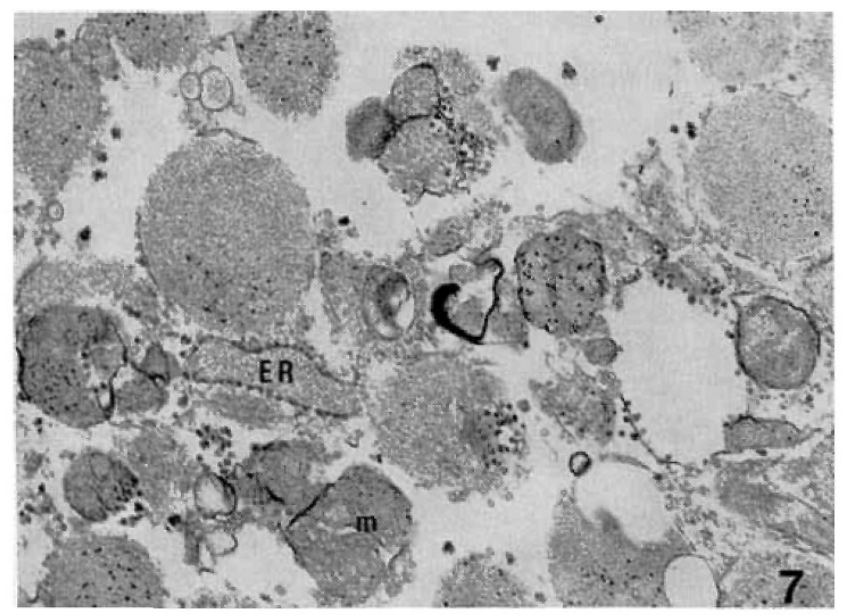

Fig. 7. High magnification of Type $I$ inclusion, same sample as Figure 6, showing granular ruthenium red staining. ER: Endoplasmic reticulum. $m$ : Mitochondria. $\times 25,000$.

associated with reduced cell viability. As described by Ceccarini and Eagle [4, 5], the $\mathrm{pH}$ optimum for growth of normal diploid cells in culture is around 7.8 , although this varies somewhat from strain to strain. We have confirmed their observations [21] and found that $\mathrm{pH}$ optimum from growth for all the human diploid strains used in the present study is around 7.8 in spite of the remarkable morphologic changes which take place at this proton concentration.

\section{Discussion}

We have earlier shown that the lysosomal function of mucopolysaccharide degradation in cultured human fibroblasts is progressively inhibited as the $\mathrm{pH}$ of the growth media is increased [21]. The finding of increased amount of acid phosphatase as demonstrated histochemically might indicate that this enzyme is not subject to $\mathrm{pH}$-induced inactivation. However, demonstration of enzyme activity in fixed cells or cell homogenates against artificial substrates in buffered solutions is no proof that this enzyme has activity in the intact

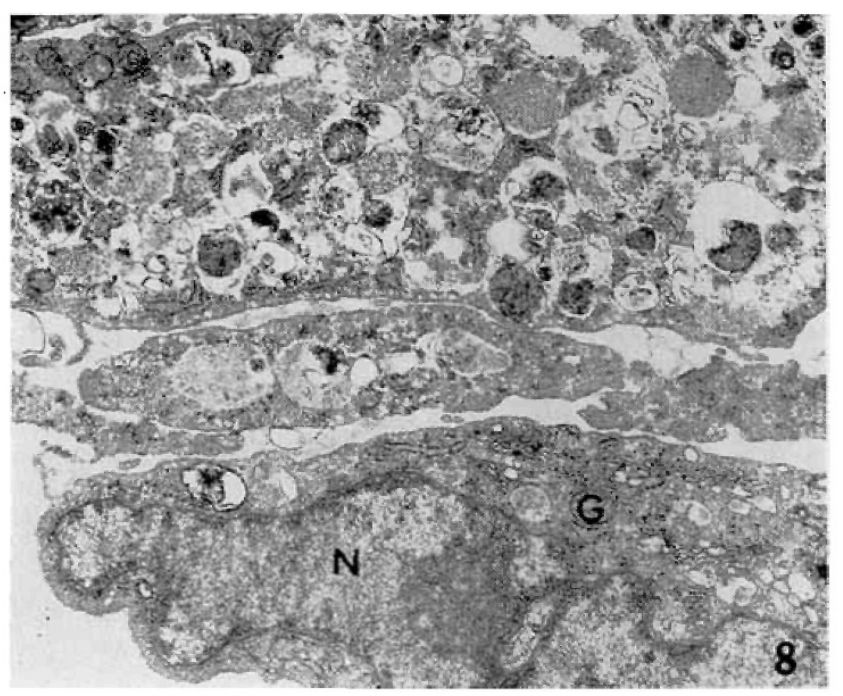

Fig. 8. Same sample as Figures 6 and 7. Acid phosphatase stain, $15 \mathrm{~min}$. Cell with normal appearance in lower portion of figure contains reaction product in the Golgi apparatus $(G) . N$ : Nucleus. Cell in upper portion contains numerous Type $I$ and Type II inclusion bodies. $\times 9,000$.

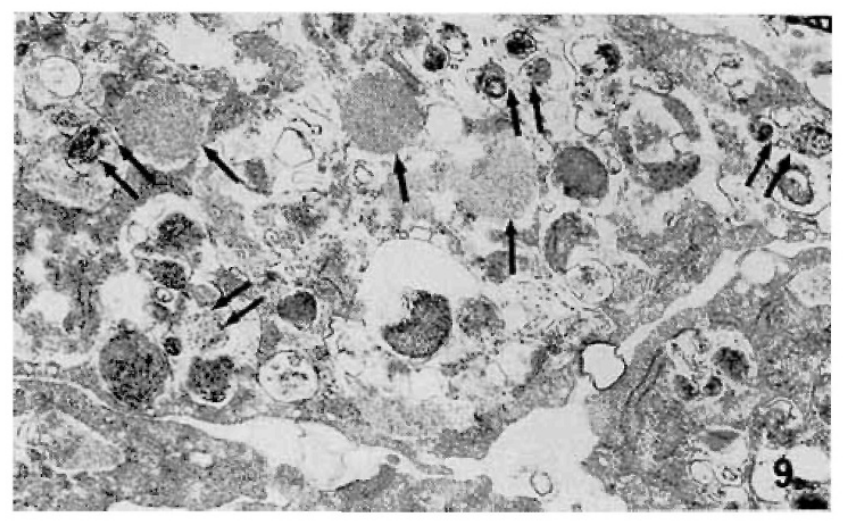

Fig. 9. Enlargement of portion of cell shown in Figure 8. Type $\mathbf{I}$ inclusions (single arrow) do not show acid phosphatase activity. Type II inclusions (double arrows) are acid phosphatase positive. $\times 25,000$. 
living cell. Whether the specific activities of other lysosomal enzymes are influenced by medium $\mathrm{pH}$ is under investigation and the results will be reported elsewhere.

The consequences of an increase in medium $\mathrm{pH}$ on the morphology of cultured human fibroblasts are compatible with a severe inhibition of lysosomal activities. The cell increases in size, and there is a drastic increase in the number of cytoplasmic bodies. These bodies could be divided into two rough groups, although intermediate types were occasionally seen. Type I had a homogeneous matrix, stained slightly with ruthenium red, was usually not membrane bound, and exhibited no acid glycerophosphatase activity. The nature and origin of these bodies are unclear. The fact that some of them were limited by a membrane raises the possibility that some sensitive membrane could have been removed during preparation of the cells. However, the bodies do not qualify as lysosomes. Type II contained whorles of membranes and inhomogeneous matrix which was acid phosphatase positive but did not stain with ruthenium red. Bodies of this type fill the criteria for lysosomal bodies, and some of these could be defined as autophagic vacuoles. The significance of the ruthenium red staining is unclear. Although ruthenium red stains mucopolysaccharides and lipids, the exact mechanism or specificity of the staining reaction is not known [23, 24]. In the present study lipid droplets were not stained by ruthenium red.

de Duve [8] has recently expanded the lysosomal concept and discusses the exoplasmic and endoplasmic space of the vacuome. In his terminology, the results of alkaline $\mathrm{pH}$ on cell morphology may be a pronounced increase in the exoplasmic space, which includes both secondary lysosomes and endocytic vesicles. We believe that this $\mathrm{pH}$ effect is best explained by assuming a progressive loss of lysosomal function as the proton concentration of the medium is lowered. There is good evidence to believe that material trapped in secondary lysosomes can be removed from these bodies only after degradation $[6,11]$. Since materials are constantly transferred to lysosomes, defective enzyme activities might explain the accumulation of the lysosomes which were observed. The accumulation of the Type $I$ body is more difficult to explain, but we suggest that they may represent accumulations of macromolecules normally degraded by the cells.

Some lysosomes contained recognizable cell organelles such as mitochondria when grown at high $\mathrm{pH}$.
This suggests increased autophagic activities in such cells. Autophagic processes can be induced in vivo by a variety of agents [10] and is usually thought to be a consequence of toxic effects resulting in increased turnover of cell organelles. However, this is not necessarily the explanation in the present case. The processes of autophagy might be normal except for defective lysosomes; thus accumulation of material in various degree of digestion was seen. It should be remembered that these changes are not reflected in decreased cell viability, since the alkaline $\mathrm{pH}$ actually stimulates cell growth $[4,5,21]$.

The molecular basis for this $\mathrm{pH}$-induced inhibition of lysosomal function (or functions) is not known. We do not know whether it is a specific or generalized phenomenon. We do not believe, however, that it reflects inhibition of protein synthesis [21], but rather that lysosomal factors in situ are progressively altered as proton concentration changes. This may be an effect either on the hydrolytic enzymes themselves, on lysosomal or cell membranes, or on all of these. The pH effects on membrane configuration are well known [22] and these changes could interfere with membrane-bound enzymes as well as with the important process of membrane fusion. The possibility that the organic buffers per se should be responsible for the observed inhibition of lysosomal function, has been excluded in an earlier paper [21].

Hanai et al. [13] have recently studied the ultrastructure of cultured cells from patients with I-cell disease. These cells are characterized by a great increase in vesicular bodies, some of which contain pleomorphic membranous bodies and recognizable cell organelles. We have observed similar changes in $\mathrm{I}$-cells cultivated in our laboratory (Figs. 10 and 11) and it is remarkable that this morphology is indistinguishable from that observed in all our normal cell strains when they have been grown in alkaline conditions.

With vital staining, a similarity is also found between I-cells cultivated at neutral $\mathrm{pH}$ and normal cells at high $\mathrm{pH}$ [19]. Although neutral red is concentrated in the lysosomes of the living cell [1], we have found that normal fibroblasts at neutral $\mathrm{pH}$ are poorly stained, if at all, when neutral red is added to the medium. However, when I-cells at neutral pH or normal cells at high $\mathrm{pH}$ are exposed to neutral red in the same concentration for 2-3 min, the whole cytoplasm becomes brilliant red. Light microscopy shows that the dye is contained in small vesicles in the cytoplasm, and one cannot distinguish any difference between I-cells 
and normal cells at high $\mathrm{pH}$. It is tempting to speculate that the mutation in I-cell disease affects the $\mathrm{pH}$ optimum of some important lysosomal function (or functions). This may result in the elimination of several lysosomal functions at the physiologic $\mathrm{pH}$. In any case, it is quite clear that morphologic studies aimed at detecting genetic defects in cells cultivated in alkaline medium are meaningless.

Tulkens et al. [29] have studied the effect of antibodies to lysosomal enzymes on cultured rat fibroblasts. A morphologic picture simulating a form of stor-

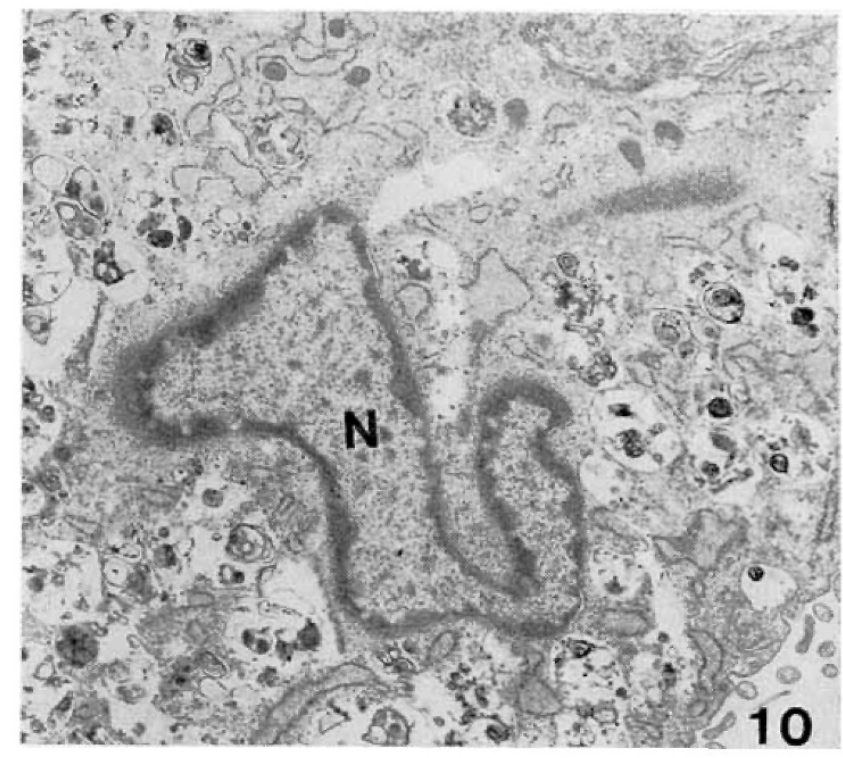

Fig. 10. Fibroblast cultured at $\mathrm{pH} 6.8$ from a patient with I-cell disease. The cytoplasm is filled with Type II inclusion bodies consisting primarily of whorls of membranes. $\times 12,000$.

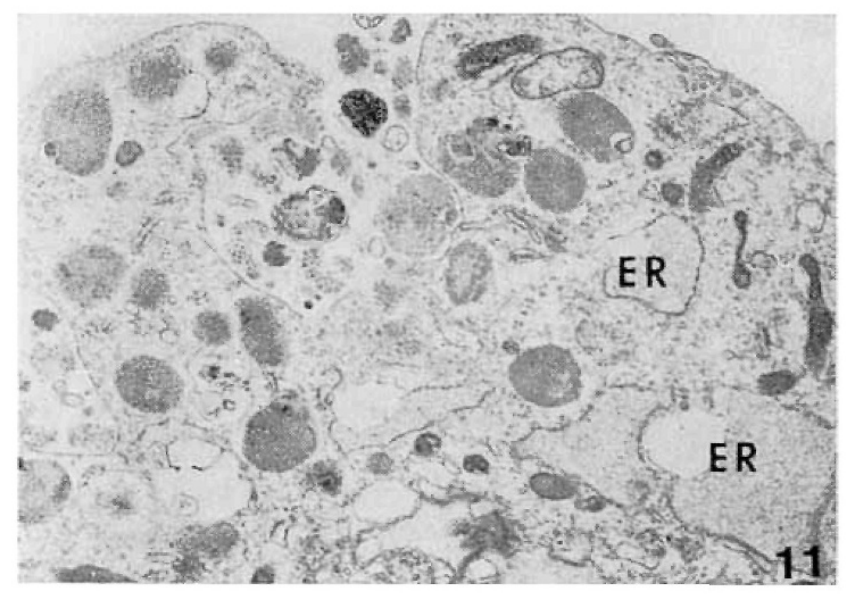

Fig. 11. Same sample as Figure 10, showing accumulation of type I inclusions. $\times 17,000$ age disease resulted, and it was thought to be caused by the inhibition of lysosomal hydrolases by pinocytosed antibodies. Homewood et al. [17] have recently proposed that chloroquin kills the malarial parasite by increasing the $\mathrm{pH}$ of the plasmodial lysosome. We have found that chloroquin indeed interferes with lysosomal function in normal human fibroblasts in much the same way as an increase in medium $\mathrm{pH}$ [19]. The expression of lysosomal function in cultured cells is therefore inhibited not only by genetic defects, but also by chemical $(\mathrm{pH})$, pharmacologic and immunologic methods. It is clear that these results strongly underline the importance of proper controls as well as controlled conditions when attempting to diagnose genetic defects in cultured cells $[3,14,26]$.

\section{Summary}

The influence of changes in extracellular $\mathrm{pH}$ on the ultrastructure of cells has been studied using normal human fibroblasts in culture. A picture resembling a lysosomal storage disease developes rapidly when the $\mathrm{pH}$ of the medium is above the physiologic range. The number of vacuoles increases and these could be divided into two groups on the basis of morphology, histochemistry, and ruthenium red staining. Only one type could be classified as a lysosome. It is proposed that these morphologic changes result from an inhibition of the normal lysosomal function (or functions) as the extracellular $\mathrm{pH}$ is increased.

\section{References and Notes}

1. Allison, A. C., AND Young, M. R.: Vital staining and fluorescence microscopy of lysosomes. In: J. T. Dingle and H. B. Fell: Lysosomes in Biology and Pathology, Vol. 2, p. 600. (North-Holland Publishing Company, Amsterdam, 1969).

2. Bartman, J., AND Blanc, W. A.: Fibroblast cultures in Hurler's and Hunter's syndromes. Arch. Pathol. (Chicago), 89: 279 (1970).

3. Bergsma, D., ANd Motulsky, A. G. (editors): Symposium on intrauterine diagnosis. Birth Defects: Original Article Series, Vol. VII, No. 5 (1971).

4. CeccarinI, C., AND EAGLe, H.: $\mathrm{pH}$ as a determinant of cellular growth and contact inhibition. Proc. Nat. Acad. Sci. U. S. A., 68: 229 (1971).

5. Ceccarini, C., and Eagle, H.: Induction and reversal of contact inhibition of growth by $\mathrm{pH}$ modification. Nature New Biol., 233: 271 (1971).

6. Conn, Z. A., AND Fedorko, M. E.: The formation and fate of lysosomes. In: J. T. Dingle and H. B. Fell: Lysosomes in Biology and Pathology, Vol. 1, p. 43. (North-Holland Publishing Company, Amsterdam, 1969).

7. Ducketr, S., Christian, J. C., Thompson, J. N., ANd Drew, A. L.: The ultrastructure of metachromatic bodies in cultured fibroblasts in Hunter's syndrome. Develop. Med. Child Neurol., 11: 764 (1969). 
8. DE Duve, G.: The lysosome in retrospect. In: J. T. Dingle and H. B. Fell: Lysosomes in Biology and Pathology, Vol. 1, p. 3. (North-Holland Publishing Company, Amsterdam, 1969).

9. EAGLE, H.: Buffer combinations for mammalian cell culture. Science, 174: $500(1971)$.

10. ERICsson, J. L. E.: Mechanism of cellular autophagy. In: J. T. Dingle and H. B. Fell: Lysosomes in Biology and Pathology, Vol. 2, p. 345. (North-Holland Publishing Company, Amsterdam, 1969).

11. Fratantoni, J. C., Hall, C. W., and Neufeld, E. F.: The defect in Hurler's and Hunler's syndromes: Faulty degradation of mucopolysaccharide. Proc. Nat. Acad. Sci. U. S. A., 60: 699 (1968).

12. Gomori, G.: An improved histochemical technic for acid phosphatase. Stain Technol., 15:81 (1950).

13. Hanai, J., Leroy, J. ANd O'Brien, J.: Ultrastructure of cultured fibroblasts in I-cell disease. Amer. J. Dis. Child., 122: 34 (1971).

14. HARRIS, M. (editor): Early diagnosis of human genetic defects-Scientific and ethical consideration. Department of Health, Education, and Welfare Publication No. 72-25. (National Institutes of Health, Bethesda, Md., 1972).

15. Hers, H. G.: Inborn Iysosomal diseases. Gastroenterology, 48: 625 (1965).

16. Hers, H. G., AND VAN Hoof, F.: Genetic abnormality of lysosomes. In: J. T. Dingle and H. B. Fell: Lysosomes in Biology and Pathology, Vol. 2, p. 19. (North-Holland Publishing Company, Amsterdam, 1969).

17. Homewood, C. A., Warhurst, D. C., Peters, W., and BagGALEY, V. C.: Lysosomes, $\mathrm{pH}$, and the anti-malarial action of chloroquine. Nature, 235: 50 (1972).

18. Leroy, J. G., and DeMars, R. I.: Mutant enzymatic and cytological phenotypes in cultured human fibroblasts. Science, 157: 804 (1967).

19. LrE, S. O.: Drug-induced inactivation of lysosomal functions in normal cultured human fibroblasts. In preparation.
20. LIE, S. O.: Vital staining of I-cells and of normal human fibroblasts as a function of medium $\mathrm{pH}$. In preparation.

21. Lre, S. O., McKusick, V. A., ANd Neufeld, E. F.: Simulation of genetic mucopolysaccharidoses in normal human fibroblasts by alteration of medium pH. Proc. Nat. Acad. Sci. U. S. A., 69: 2361 (1972).

22. LucY, J. A.: Lysosomal membranes. In: J. T. Dingle and H. B. Fell: Lysosomes in Biology and Pathology, Vol. 2, p. 313. (North-Holland Publishing Company, Amsterdam, 1969).

23. Luft, J. H.: Ruthenium red and violet I. Chemistry, purification and mechanism of action. Anat. Rec., 171: 347 (1971).

24. Lufr, J. H.: Ruthenium red and violet II. Fine structural localization in animal tissues. Anat. Rec., 171: 396 (1971).

25. McKusick, V. A.: Human genetics. Annu. Rev. Genet., 4: 1 (1970).

26. Milunskx, A., Littlefield, J. M., AND Kanfer, J. N., Kolodny, E. H., Shir, V. E., And Atkins, L.: Prenatal genetic diagnosis. New Eng. J. Med., 283: 1370, 1441, 1498 (1970).

27. Resibors, A., Tondeur, M., Mockel, S., AND Dustin, P.: Lysosomes and storage disease. Int. Rev. Exp. Pathol., 9: 93 (1970).

28. Tondeur, M., Vamos-Hurwitz, E., and Loeb, H.: Contributions recentes de la microscopie electroniques et de la culture de tissus dans l'etude de certaines maladies de stockage: mucopolysaccharidoses et lipidoses. Acta Paediat. Belg., 24: 355 (1970).

29. Tulkens, P., Trouet, A., ANd van Hoof, F.: Immunological inhibition of lysosome function. Nature, 288: 1282 (1970).

30. Falcon Plastics, Division of Bioquest, Oxnard, Calif.

31. The present address of Dr. Sverre O. Lie is: Department of Pediatrics, University Hospital, Riks hospitalet, Oslo 1, Norway.

32. Requests for reprints should be addressed to: BRIAN H. ScHOFIELD, M.D., Orthopaedic Research Laboratory, C.M.S.C. 9110, Johns Hopkins Hospital, Baltimore, Md. 21205 (USA).

33. Received for publication September 29, 1972. 